\title{
An update in regulatory of the Brazilian herbal medicines and medicinal plants professional prescribers
}

\begin{abstract}
Background: The introduction of Herbal Medicines Prescriptions in Primary Health Care in Brazil was important to improve the herbal medicine access from PHC patients. However, the lack of knowledge about how to prescription them it is a problem in the Primary Health Care, because the Brazilian Herbal Medicine and Medicinal Plant professionals prescriber do not have a minimum academic background in medicinal plants and are not aware of their legal qualification to prescribe them, nor do they have minimum consultation tools to prescriber medicinal plants in a rational and safe manner for the patient, so that these professionals prefer to choose allopathic medicines. In this sense, we did a review about a legal qualification for each Brazilian medicinal plants and herbal medicine professional prescriber to understand how they may help the patients to have access to medicinal plants and herbal medicines in the Brazilian Primary Health Care.
\end{abstract}

Objective: The aim of this study was to review of using herbal medicine according to Pharmacopoeia in the regulatory field.

Methodology: A literature review was conducted in databases as PubMed, Science Direct, Web of Science, Cochrane Library, Google Scholar and other regulatory affairs databases about updates in Brazilian Herbal Medicine and Medicinal Plant Professionals Prescriber.

Results and discussion: Studies show that there is a low adherence regarding the prescription of Medicinal Plants and Herbal Medicines in Primary Health Care, although there is a phytotherapeutic memento to assist in the prescription. These gaps may be related to the lack of knowledge and discouragement of health professionals due to the budget deficit of the Primary Health Care and the non-insertion of herbal medicine knowledge already in undergraduate courses. In addition, misleading popular knowledge and its transmission from generation to generation about PMFs may be causing irrational and unsafe indications.

Conclusion: Although the inclusion of MPBP in the practice of clinical phytotherapy was important, the health professional prescribers still unknown herbal medicine and medicinal plants practice, contributing $\mathrm{t}$

Keywords: professional prescriber, regulatory affairs, primary health care, herbal medicine, medicinal plants
Volume 8 Issue 2 - 2020

\section{Mayara de Azeredo Rezende}

Biodiversity and Health Innovation Center, Drug Technology Institute, Farmanguinhos/Fiocruz, Brazil

\section{Correspondence: Mayara de Azeredo Rezende, Coordinating Advisor from Innovation in Biodiversity and Health Center, Drug Technology Institute, Farmanguinhos/Fiocruz, Comandante Guaranys Avenue, 447-Zip code: 22775-903, Jacarepaguá, Rio de Janeiro, Brazil, Tel +55 (2l) 3348-504l, Email mayara.rezend@far.fiocruz.br}

Received: January 22, 2020 | Published: March 19, 2020
Abbreviations: WHO, world health organization; PHC, primary health care; MP, medicinal plants; HM, herbal medicines; UHS, unified health system; NPICP, national policy for integrative and complementary practices; ÑPMHM, national policy for medicinal plants and herbal medicines; ANVISA, national health surveillance agency; RCB, resolution of the collegiate board; MPBP, phytotherapeutic memento of the Brazilian pharmacopeia; THP, traditional herbal product; TM, traditional medicine; CFO, federal council of dentistry; CFF, federal council of pharmacist; CFN, federal council of nutrition; COFFITO, federal council of physiotherapist; COFEN, federal council of nurse

\section{Introduction}

The World Health Organization (WHO) regarding the importance and magnitude of the Medicinal Plants and the Herbal Medicines (MPHM) in people's daily lives, citing respectively $96 \%, 71 \%$ and $98 \%$ of the individuals interviewed. Although the MPHM is an important popular practice, the WHO also regarding the safe use of them in its guidelines, encouraging the added value of the traditional use of these therapeutic resources in Primary Health Care (PHC). ${ }^{1-3}$

In Brazil, the MPHM was institutionalized nationally by the Unified Health System (UHS) with the publication of the National Policy for Integrative and Complementary Practices (NPICP) in 2006, a document that served as the basis for the publication of the National Policy for Medicinal and Phytotherapeutic Plants (NPMPHM) in 2006, through Federal Decree No. 5813, of June 22, 2006, which establishes guidelines and priority lines for the development of actions aimed at ensuring the safe access and rational use of medicinal plants an herbal medicines, the development of technologies and innovations, as well as the strengthening of production chains and arrangements, the sustainable use of Brazilian biodiversity and the development of the Health Industrial Productive Complex. ${ }^{4,5}$ The guidelines are mostly published later, in 2008, through the Medicinal and Phytotherapeutic Plants Program, approved by Interministerial Ordinance No. 2960, of December 9, $2008 .^{6}$ 
After the publication of the NPMPHM, the regulatory norms underwent significant changes according to the Brazilian National Health Surveillance Agency (ANVISA). ${ }^{7}$ Through the years, Anvisa has published one of the most relevant documents in Medicinal Plants and Herbal Medicines categories, the Resolution No. 26, of May 13 rd on 2014, which provides for the registration of herbal medicines and the registration and notification of traditional herbal products. ${ }^{8}$ Through the Resolution No. 26/14, Anvisa ordered the class "herbal medicines" in two categories: Herbal Medicine (HM) and Traditional Herbal Product (THP). The main difference between the two categories is that the HM proves its safety and efficacy through clinical studies, while the THP proves the safety and effectiveness by the traditional use through the time of use in the technical-scientific literature. In this sense, the publication of RDC 26/14 led to the maturing of discussions not only about the process of phytotherapy registration in Brazil, but also the correct prescription of MPHB. ${ }^{9}$

In this context, ten years after the implementation of NPMPHM in an attempt to reduce existing gaps to contribute to rational herbal medicine prescription, Anvisa, through the Decree No. 84 of June 17th on 2016, published the Memento Phytotherapic of the Brazilian Pharmacopeia (MPBP)., ${ }^{9} 10$ The purpose of the MPBP is to guide the prescription of the MP and HM, based on scientific evidence, with information on identification, popular and scientific nomenclature, part used, therapeutic indications, contraindications, precautions for use, adverse effects, drug interactions, pharmaceutical forms, routes of administration, dosage, duration of use, overdose, prescription, main chemical classes, safety, efficacy and references. ${ }^{10}$

In this sense, after three years of the MPBP publication, it was observed the low adherence by health professionals prescribers in both to prescription medicinal plants and herbal medicines, often due to the discredit and lack of therapy and, mainly, the fact that few universities have its curriculum, disciplines focused on the use and prescription of herbal medicines, which makes it difficult for prescribing professionals to qualify in these areas. In addition, the most professional's prescriber unaware the real legal qualification to prescribe them and in some cases, it may be an important problem because they do not prescribe some types of medicinal plants and herbal medicines because it causes acute toxicity or may produce hallucinogen effects. ${ }^{9,10}$ Thus, it is of utmost importance to analyze the regulatory framework of medicinal and phytotherapic plants professionals' prescribers. Therefore, the aim of this was review of using herbal medicine according to Pharmacopoeia in the regulatory field.

\section{Material and methods}

To carry out this work, we performed the literature review that was conducted in an open access databases and other regulatory affairs databases about updates in Brazilian Herbal Medicine and Medicinal Plant Professionals Prescriber. It is noteworthy that the basis of this work will not be restricted to the literature review, we included publications and books with relevant content to complement the research and to enrich the discussion on the topic. Regarding the regulatory content, all laws, resolutions, decrees and normative instructions, as well as ordinances, published in Brazil covering the regulation of prescribing professionals for herbal medicine and medicinal plants, will be analyzed. The full text of the legal documents will be searched on the websites of the Ministry of Health, the National Health Surveillance Agency, the Federal Official Gazette and other resolutions of the deliberative councils of prescribing professionals. The analysis will mainly consider the technical requirements required for prescribing medicinal plants and herbal remedies. The data was tabulated with the help of Microsoft Office Excel version 2016.

\section{Results}

We found 9 resolutions from many different Professional Prescriber Councils that described the mainly habilitation that each professional may have in medicinal plant and herbal medicine prescription as show in Table 1.

Table I Specific qualification to prescribing medicinal plants and herbal medicines at HPC

\begin{tabular}{|c|c|c|c|c|}
\hline No & $\begin{array}{l}\text { Professional } \\
\text { Category }\end{array}$ & $\begin{array}{l}\text { Regulation } \\
\text { number }\end{array}$ & $\begin{array}{l}\text { Year of the } \\
\text { publication }\end{array}$ & Description \\
\hline I & $\begin{array}{l}\text { Surgeon } \\
\text { Dentist }\end{array}$ & $\begin{array}{l}\text { Resolution } \\
\mathrm{n}^{\circ} 82\end{array}$ & 2008 & $\begin{array}{l}\text { It recognized and regulated the use by the dentist of integrative and complementary practices to oral health, } \\
\text { and in art. } 7^{\circ} \text {, there is the qualification of this professional for phytotherapy, according to the requirements } \\
\text { described. }\end{array}$ \\
\hline 2 & Nurse & $\begin{array}{l}\text { Resolution } \\
n^{\circ} 518\end{array}$ & 2018 & $\begin{array}{l}\text { Established and registered as Alternative Therapies, among them Phytotherapy, as a specialty and / or } \\
\text { professional nursing qualification. }\end{array}$ \\
\hline \multirow{2}{*}{3} & \multirow{2}{*}{ Pharmacist } & $\begin{array}{l}\text { Resolution } \\
n^{\circ} 459\end{array}$ & 2007 & Provides for the pharmacist's duties within the scope of the HM and provides other measures. \\
\hline & & $\begin{array}{l}\text { Resolution } \\
n^{\circ} 546\end{array}$ & 2011 & $\begin{array}{l}\text { Provides for the therapeutic indication of medicinal plants and herbal remedies without prescription and their } \\
\text { registration and other measures. }\end{array}$ \\
\hline \multirow{2}{*}{4} & \multirow{2}{*}{ Physiotherapist } & $\begin{array}{l}\text { Resolution } \\
n^{\circ} 380\end{array}$ & 2010 & $\begin{array}{l}\text { Regulated the use of integrative and complementary practices for physical therapists, including herbal } \\
\text { medicine. }\end{array}$ \\
\hline & & $\begin{array}{l}\text { Judgement } \\
n^{\circ} 611\end{array}$ & 2017 & $\begin{array}{l}\text { It standardized the use and / or indication of substances of free prescription by the physiotherapist. Among the } \\
\text { categories described in the judgment are herbal medicines and medicinal plants. }\end{array}$ \\
\hline 5 & Doctors & $\begin{array}{l}\text { Resolution } \\
n^{\circ} 1.246\end{array}$ & 1988 & $\begin{array}{l}\text { Federal Medical Council Resolution No. I,246 / } 88 \text { attributed the prescription of medicines in general to the } \\
\text { medical professional. However, the prescription of herbal medicines has been regulated since } 2006 \text {, from the } \\
\text { creation of the National Policy on Integrative and Complementary Practices (NPPICP) and the National Policy } \\
\text { on Medicinal and Herbal Plants (NPMPHM). }\end{array}$ \\
\hline \multirow[b]{2}{*}{6} & \multirow[b]{2}{*}{ Nutritionists } & $\begin{array}{l}\text { Resolution } \\
n^{\circ} 525\end{array}$ & 2013 & $\begin{array}{l}\text { It regulated the practice of Phytotherapy by the nutritionist, giving it the competence to prescribe medicinal } \\
\text { plants and medicinal teas, herbal medicines, traditional herbal products and master herbal preparations in } \\
\text { addition to the dietary prescription and other measures. }\end{array}$ \\
\hline & & $\begin{array}{l}\text { Resolution } \\
n^{\circ} 556\end{array}$ & 2015 & $\begin{array}{l}\text { Update of CFN Resolution No. } 556 / 15 \text {, including the prescription of medicinal plants and medicinal teas can be } \\
\text { given by the nutritionist, regardless of the title of specialization in the area, as well as the prescription of herbal } \\
\text { medicines, traditional herbal products and masterful preparations of herbal medicines, as a complement to a } \\
\text { dietary prescription, the nutritionist is allowed as long as he holds the title of specialist in Phytotherapy. }\end{array}$ \\
\hline
\end{tabular}




\section{Discussion}

The Primary care was defined as essential health care, based on practical methods and technologies, scientifically well-founded and socially acceptable, made available to families and the community, ${ }^{11}$ guaranteed by the Federal Constitution of 1988 and the creation of the UHS Organic Law. ${ }^{12-14}$

In this sense, the use of phytotherapy in PHC aims to increase therapeutic resources, rescue popular knowledge, preserve biodiversity, promote environmental agroecology, reduce technological dependence, stimulate the sustainable use of Brazilian biodiversity, valorization and preservation of traditional knowledge and the rational and appropriate use of these products, in addition to local actions that provide and encourage the production and use of medicines originating from biodiversity. ${ }^{2,15}$ In this context, we found 12 selected studies demonstrated that there is an acceptance by the prescribing professionals and by UHS users to prescribe and use medicinal plants and herbal medicines as pharmacological therapy for the treatment of various pathologies.

A several studies affirmed that $80 \%$ of people in developing countries in the world, as a way of guaranteeing this primary health care, basically depend on Traditional Medicine (TM), and approximately $85 \%$ of TM involves the use of medicinal plants. ${ }^{16,17}$ In Brazil, the population of the North and Northeast regions are the most benefited with medicinal plants and herbal medicines. And it was constated that Rio Grande do Sul State is the most state that incentives the prescription and the use of herbal medicine and medicinal plants through a strong policy statement. For example, in the municipality of Cascavél-Paraná, one of each selected study it has interviewed approximately 50 families constituting the area covered by the HPC in the municipality. Within this sample universe, $96 \%$ of users indicated that they use medicinal plants to treat less serious illnesses and diseases. In addition, $86 \%$ of these users cultivate medicinal plants, which they use. As for the possibility of prescribing medicinal plants at HPC to replace industrialized drugs, $100 \%$ of the interviewed users answered that they would use them to treat healthrelated problems. ${ }^{13,16,17}$ Other studies also confirmed this sentence and they affirmed that the most health professionals had a short course about medicinal plants and herbal medicines. Only $77.7 \%$ of doctors reported knowing some type of herbal medicine. .,2,14,18 $^{1}$

All results together showed us that are a lack of knowledge of health professionals on the theme, the actions/services institutionalized by the Ministry of Health (MS) involving medicinal plants and phytotherapy in UHS, although the MS maintains a list of plants of therapeutic interest, the National List of Plants of Interest to UHS (RENISUS), which lists 71 species of plants of popular medicinal use and which need further investigation. The plants with their validated indications will be part of National List of Medicinal Plants-RENAFITO, which is the national list of medicinal plants and herbal medicines that will subsidize the prescription of herbal medicines in the scope of UHS health services, one of the objectives of NPICP and one of the actions present in the NPMPHM and in National Program for Medicinal Plants and Phytotherapics. ${ }^{19,20}$

But despite the gaps found, the advancement in the regulatory framework allowed a better adjustment of the categories of herbal medicines and the recovery of their traditional knowledge. Historically, the doctor is the professional qualified for the diagnosis and prescription of medicines in human medicine. In medicine, phytotherapy is not considered a specialty, but it is allowed for the doctor to prescribe herbal medicines. ${ }^{20}$

In this context, the Federal Council of Odontology (CFO) regulated the qualification for the prescription of PMFs by the dentist through Resolution CFO $\mathrm{n}^{\circ} 82 / 08$, which recognized and regulated the use by the dentist of integrative and complementary health practices buccal. ${ }^{21,22}$ In addition, the Federal Council of Nurses (COFEN) has been trying to readjust the premises that can rehabilitate this professional to prescribe herbal medicines outside the scope of the PHC. Through COFEN Resolution No. 581/18, which updated, within the scope of the COFEN System/Regional Nursing Councils, the procedures for the Registration of Lato and Stricto sensu Graduate Titles granted to nurses and approved the list of specialties. ${ }^{23}$

The constitutive legal action in phytotherapy by the pharmacist is regulated by the Federal Pharmacy Council (CFF) through Resolution CFF $n^{\circ} 459 / 07$, which provides for the pharmacist's duties within the scope of the HMs and provides other measures. ${ }^{24}$ Furthermore, Resolution CFF $n^{\circ} 546 / 11$, which provides for the therapeutic indication of medicinal plants and herbal remedies without prescription and their registration and gives other measures, allowed the pharmacist, within the legal parameters, to indicate HM and THP exempt from medical prescription for low risk pathologies. A pharmacist who working in the public or private sector, proves one of the following qualifications is considered qualified to exercise the indication of medicinal plants and/or phytotherapics: a) has attended the course of phytotherapy with a minimum workload of 60 hours pharmacy undergraduate course, complemented with an internship in handling and/or dispensing MP or HB, of at least 120 hours, at the higher education institution itself, in pharmacies that handle and / or dispense MP or HM or in herbal distribution programs in UHS, with educational institutions; $b$ ) title of specialist or specialization course in phytotherapy that meets the relevant resolutions of the Federal Council of Pharmacy in force..$^{20,25}$ In 2013, the CFF published, concomitantly, 2 resolutions that concretized the qualification of the pharmacist as a prescribing professional in general. The first prescriptive regulation was through Resolution CFF No. 585/13, which regulates the clinical duties of the pharmacist and provides other measures. The second regulation was by Resolution CFF $n^{\circ} 586 / 13$, which, in fact, regulates the pharmaceutical prescription and provides other measures. ${ }^{26,27}$

Since 2010, the Federal Council of Physiotherapy and Occupational Therapy (COFFITO) has regulated the use of integrative and complementary practices for physical therapists through COFFITO Resolution No. 380/10. Among the integrative practices enabled for the use of physiotherapists, there are: phytotherapy, body practices, manual and meditative, floral therapy, magnetotherapy, anthroposophical physiotherapy, thermals/crenotherapy/balneotherapy and hypnosis. As for the qualification in these practices, the physiotherapist must prove to COFFITO the knowledge certification within the integrative and complementary practices. Under the terms of the resolution, the physiotherapist who presents titles that prove the mastery of Integrative Practices, object of Resolution COFFITO No. 380/10, will be qualified. The titles, to which you allude, must originate from: a) Higher Education Institutions; b) Institutions specially accredited by MEC, the Brazilian Ministry of Education; c) National physiotherapy entities closely related to the practices authorized by this resolution. Despite the existence of this COFFITO Resolution No. 380/10, it was only in 2017, through a judgment No. 611/17, that the use and/ or indication of substances of free prescription by the physiotherapist 
was regulated. Among the categories described in the judgment are herbal medicines and medicinal plants. ${ }^{28,29}$

In 2013, the practice of phytotherapy by the nutritionist was regulated by the Federal Council of Nutrition (CFN) through Resolution CFN No. 525/13, which regulated the practice of phytotherapy by the nutritionist, giving it competences to, in the specific modalities, prescribe medicinal plants and medicinal teas, herbal medicines, traditional herbal products and master herbal preparations as a complement to the dietary prescription and provide other measures..$^{30}$ However, this resolution was updated by Resolution CFN No. 556/15, including that for the prescription of medicinal plants and medicinal teas it can be given by an independent nutritionist with a specialization degree in the area, as well as the prescription of herbal medicines and traditional products herbal medicines as a complement to a dietary prescription, the nutritionist is allowed as long as he holds the title of specialist in Phytotherapy. ${ }^{31}$

However, even three years after the publication of the MPBP, what is perceived is the ignorance of these health professionals in relation to the prescription of herbal medicines, often due to the discredit and the absence of therapy and, mainly, due to the fact that few universities have it in their possession. curriculum, disciplines focused on the use and prescription of herbal medicines, which makes it difficult for prescribing professionals to qualify in the area. If, on the one hand, there are government and prescribing professionals' difficulties in relation to herbal medicines, on the other, for the population, the use of herbal medicines is often confused with the use of so-called medicinal plants used in the form of extractive preparations (teas and decoctions) which do not constitute a herbal medicine, as they do not have a secure botanical identity and these correlate with the idea "what is natural, it does not hurt", even though it was found that in some municipalities in Brazilian states the population already understands what the use would be rational and safe use of herbal medicines.

\section{Conclusion}

In this work it was possible to verify the scenario about the knowledge or not of the professionals prescribed about medicinal plants and herbal medicines. Arbitrarily to all the initiatives to introduce phytotherapy in UHS, there are still professionals who unknown or prescribe them, despite the acceptance of PHC users in relation to medicinal plants and herbal medicines. From this observation, there is a need to disseminate information with specificities for each target audience. Thus, the inclusion of MPBP in the practice of clinical phytotherapy is of fundamental importance. Given the above, it is concluded that this work fulfilled its objectives, and even without exhausting the theme, it gathered useful information for health professionals to guide the study, raise awareness, raise discussions and contribute to promoting the safe and rational use of medicinal plants and herbal medicines.

\section{Acknowledgments}

None.

\section{Conflicts of interest}

The author does not have any conflicts of interest.

\section{References}

1. Fontenele RP, Souza DMP, Carvalho ALM, et al. Phytotherapy in Primary Health Care: perspectives of managers and professionals in the
Family Health Program of Teresina, Piauí, Brazil. Rev Cien Saúde Colet. 2013;18(8):2385-2394.

2. Petry K, Roman WAJ. Implantation of herbal and medicinal plants in Health System (SUS) of Três Passos/RS. Rev Bras Farm. 2012;93(1):60-67.

3. Tomazzoni MI, Negrelle ML. Popular herbal medicine: the instrumental search as a therapeutic practice. Texto Contexto-Enferm. 2006;15(1):115-121.

4. Approves the National Policy of Integrative and Complementary Practices (PNPIC) in the Unified Health System. Brazil: Ministry of Health; 2006.

5. Política Nacional de Plantas Medicinais e Fitoterápicos. Brasília: Ministério da Saúde; 2006. 60 p.

6. Approves the National Program for Medicinal Plants and Herbal Medicines and creates the National Committee for Medicinal Plants and Herbal Medicines. Brazil: Ministry of Health; 2008.

7. Rezende MA. Preparation of a manual of good practices based on a meta-analysis of phytomedicine patents. 207f. Course Conclusion Paper (Specialization)-Pharmaceuticals Technology Institute/Farmanguinhos, Oswaldo Cruz Foundation, Rio de Janeiro; 2016.

8. Provides for the registration of herbal medicines and the registration and notification of traditional herbal products. Brazil: ANVISA; 2014.

9. Oshiro MC, Miguel MD, Dias JFG, et al. The evolution of the registration and prescription of herbal medicines in Brazil from a legal and sanitary perspective. Rev Visa Debate. 2016;4(4):116-122.

10. Approves the Phytotherapeutic Memento of the Brazilian Pharmacopoeia and provides other measures. Brazil: ANVISA; 2016.

11. Assis MMA, Cerqueira EM, Nascimento MAA, et al. Primary Health Care and its articulation with the Family Health Strategy: practical, methodological and political construction. Rev APS. 2007;10(2):189-199.

12. Constituição da República Federativa do Brasil. DF: Senado Federal; 1988. $292 \mathrm{p}$.

13. Provides for the conditions for the promotion, protection and recovery of health, the organization and functioning of the corresponding services and provides other measures. Brazil: Presidency of the Republic SubSofia Civil House for Legal Affairs; 1990.

14. Reis DO, Araújo EC, Cecílio LCO. Public Health Policies: Unified Health System. UNA-SUS/UNIFESP. 2011; 18p.

15. Ferreira MGR. Social aspects of herbal medicine. Porto Velho, RO: Embrapa Rondônia; 2006. 14 p.

16. Silva MIG, Gondim APS, Nunes IFS, et al. Use of herbal medicines in basic units of attention to family health in the municipality of Maracanaú (CE). Rev Bras Farmacog. 2006;16(4):445-462.

17. Souza AJA. Use of medicinal plants in the municipality of Benevides Pará: elaboration of the phytotherapic memento and construction of the municipal policy of medicinal and phytotherapic plants. Dissertation (Master's Degree)-Federal University of Pará, Environment Center, Belém; 2011.

18. Varela DSS, Azevedo DM. Physicians' knowledge and herbal practices in the family health strategy. Trab Educ Saúde. 2014;12(2):273-290.

19. Medicinal Plants of Interest to SUS-Renisus. Brazil: Ministry of Health; 2009.

20. Macedo JAB. Medicinal plants and herbal medicines in primary health care: contribution to prescribing professionals. 2016. 49f. Course Conclusion Paper [Post-Graduation in Innovation Management in Phytomedicines]. Instituto de Tecnologia em Fármacos/Farmanguinhos, Fundação Oswaldo Cruz: Rio de Janeiro; 2016. 58 p. 
21. Recognizes the use by dentists of integrative and complementary oral health practices. Rio de Janeiro: CFO; 2008. 15 p.

22. Lower complementary standards for qualification in Integrative and Complementary Practices. Rio de Janeiro: CFO; 2008.

23. Updates, within the scope of the COFEN System/Regional Councils of Nursing, the procedures for Registration of Lato and Stricto Sensu Graduate Titles granted to Nurses and approves the list of specialties. Rio de Janeiro: COFEN; 2018.

24. Provides for the duties of the pharmacist in the field of medicinal plant and herbal medicines and provides other measures. Brazil: CFF; 2007.

25. Provides for the pharmaceutical indication of medicinal plants and herbal medicines free from prescription and its registration. Brazil: CFF; 2011.

26. Regulates clinical assignments pharmacist and makes other arrangements Brazil: CFF; 2013. 11 p.
27. Regula a prescrição farmacêutica e dá outras providências. Brasilia: CFF; 2013.

28. Regulates the use by the Physiotherapist of Integrative and Complementary Health Practices and provides other measures. Brazil: COFFITO; 2010.

29. Standardization of the use and/or indication of substances of free prescription by the physiotherapist. Brazil: COFFITO; 2017.

30. Regulates the practice of Phytotherapy by the nutritionist, assigning him the competences to, in the modalities that specify, prescribe medicinal plants and medicinal teas, herbal medicines, traditional herbal products and master herbal preparations as a complement to the dietary prescription and provides other measures. Brazil: Federal de Nutricionistas; 2013.

31. Amends Resolutions $n^{\circ} 416$, of 2008, and $n^{\circ}$ 525, of 2013, and adds provisions to the regulation of the practice of Phytotherapy for the nutritionist as a complement to the dietary prescription. Brazil: CFN; 2015 . 